\title{
Diagnóstico sorológico da brucelose bovina em animais adultos vacinados com dose reduzida da cepa 19 de Brucella abortus ${ }^{1}$
}

\author{
Gustavo Coelho Jardim²*, Pedro Paulo Pires ${ }^{3}$, Luis Antonio Mathias ${ }^{4}$, Olímpio \\ Crisóstomo Ribeiro ${ }^{2}$ e Márcio Rubens Graf Kuchembuck ${ }^{5}$
}

\begin{abstract}
Jardim G.C., Pires P.P., Mathias L.A. \& Ribeiro O.C. \& Kuchembuck M.R.G. 2006. [Serological diagnosis of bovine brucellosis in adult herd vaccinated with Brucella abortus strain 19 reduced dose.] Diagnóstico sorológico da brucelose bovina em animais adultos vacinados com dose reduzida da cepa 19 de Brucella abortus. Pesquisa Veterinária Brasileira 26(3):177-182. Departamento de Medicina Veterinária, Universidade para o Desenvolvimento do Estado e Região do Pantanal (Uniderp), Rua Alexandre Herculano 1400, Parque dos Poderes, Campo Grande, MS 79037-280, Brazil.E-mail: gustavoj@mail.uniderp.br

The study evaluated the use of a reduced dose of the Brucella abortus strain 19 vaccine, in an adult herd negative for the disease, by serological diagnostic techniques, advocated by the Brazilian Program for Animal Brucellosis and Tuberculosis Control and Eradication, and by an indirect ELISA. The complement fixation test detecteed $46.77 \%$ positives, the rose bengal test $67.74 \%$, the mercaptoethanol with standard agglutination test $87.09 \%$ and the ELISA ID $100 \%$. The reduced dose influenced the serological diagnosis. None of the techniques reached a suitable specificity for use in the herd under those conditions, up to 3 months after vaccination.
\end{abstract}

INDEX TERMS: Bovine brucellosis, vaccination, strain 19, serological diagnosis.

RESUMO.- Com o presente trabalho avaliou-se o uso de dose reduzida da vacina produzida com a amostra 19 de Brucella abortus, em rebanho adulto negativo para a enfermidade, por meio de técnicas de diagnóstico sorológico preconizadas pelo Programa Nacional de Controle e Erradicação da Brucelose e Tuberculose Animal e por um ensaio indireto de imunoadsorção enzimática (ELISA ID). A prova de fixação de complemento detectou $46,77 \%$ de positivos, o antígeno acidificado tamponado $67,74 \%$, o 2-mercaptoetanol com soroaglutinação lenta $87,09 \%$

\footnotetext{
${ }^{1}$ Recebido em 12 de julho de 2005.

Aceito para publicação em 20 de fevereiro de 2006.

Parte da dissertação do primeiro autor no Curso de Mestrado em Clínica Veterinária, do Programa de Pós-Graduação em Medicina Veterinária, Faculdade de Medicina Veterinária e Zootecnia, Unesp, Distrito Rubião Júnior, s/nº, Botucatu, SP 18618-000.

${ }^{2}$ Depto Medicina Veterinária, Universidade para o Desenvolvimento do Estado e Região do Pantanal (Uniderp), Rua Alexandre Herculano, 1400, Parque dos Poderes, Campo Grande, MS 79037-280. *Autor para correspondência: gustavoj@mail.uniderp.br

3 Área de Sanidade Animal, Embrapa Gado de Corte, BR 262, Km 4, Campo Grande, MS 79002-970.

${ }^{4}$ Depto Medicina Veterinária Preventiva e Reprodução Animal, FCAV, Unesp, Campus de Jaboticabal, Rod. Prof. Paulo Donato Castelane, Km 5, Jaboticabal, SP 14884-900.

${ }^{5}$ Depto Clínica Veterinária, Faculdade de Medicina Veterinária e Zootecnia, Unesp, Distrito Rubião Júnior s/nº, Botucatu, SP 18618-000.
}

e o ELISA ID $100 \%$. A dose reduzida interferiu no diagnóstico sorológico. Nenhuma das técnicas apresentou especificidade adequada para uso em rebanho nestas condições, até 3 meses após a vacinação.

TERMOS DE INDEXAÇÃO: Brucelose bovina, vacinação, amostra B19, diagnóstico sorológico.

\section{INTRODUÇÃO}

A brucelose bovina é uma zoonose de distribuição mundial, cujo agente etiológico causa problemas sanitário e econômico, particularmente nos trópicos e em países com pouco investimento nas áreas de produção de leite e carne, onde sua incidência é alta (Megid et al. 2000).

Suas implicações econômicas geram barreiras internacionais ao comércio de produtos de origem animal e perdas na indústria: condenação do leite e da carne, queda de preços da carne, leite e derivados, desvalorização para o mercado externo, e altos custos com programas de controle, erradicação e pesquisas.

Reconhecendo os problemas ligados a esta doença, a maioria dos países desenvolvidos adotaram, há mais de 20 anos, medidas sanitárias destinadas à sua erradicação, obtendo êxito, como Canadá, Dinamarca, Austrália, Inglaterra, Holanda, Suécia e Japão, enquanto outros países, como a França e os Estados Unidos da América (EUA) mantêm a mesma controlada, com diminuição de sua ocorrência (Molnár et al. 2000). Até 1997, os 
EUA já haviam gasto mais de 3 bilhões de dólares com o programa de erradicação (Ferraz 1999).

As medidas sanitárias são fundamentadas em dois focos principais: o diagnóstico e a vacinação, pelos quais é possível reduzir ou prevenir a exposição dos animais ao agente infeccioso e aumentar a resistência dos rebanhos.

No diagnóstico da maioria das doenças infecciosas o fator mais importante é o isolamento por meio do cultivo, com posterior identificação do patógeno. Assim, na atualidade, somente é possível dizer que uma enfermidade infecciosa é diagnosticada com segurança depois do isolamento e identificação do agente. Porém, no caso da brucelose, isso é um processo lento e muito oneroso, principalmente pela necessidade de investigar muitos animais nos programas de vigilância. É uma doença complexa, exigindo tempo para o isolamento e identificação (7-14 dias), além de ser trabalho perigoso, por se tratar de zoonose com alto risco de infecção humana (Molnár et al. 1997). Desta forma, as provas sorológicas ocuparam lugar de destaque no diagnóstico da enfermidade.

Quanto à vacinação, até o momento, apenas amostras vivas atenuadas da bactéria desencadearam proteção. A vacina mais utilizada, responsável pela erradicação da enfermidade em alguns países, é a da cepa 19 de B. abortus (vacina B19), que apresenta como inconveniente a possibilidade de interferir no diagnóstico sorológico, além de poder infectar o homem, ocasionar orquite e epididimite nos machos e aborto em fêmeas vacinadas em final de gestação, como o fazem cepas de campo da bactéria (Brasil 2003).

Depois de um programa de erradicação em 1976, que não obteve os resultados esperados, o Departamento de Defesa Animal do Ministério da Agricultura, Pecuária e Abastecimento aprovou o Regulamento Técnico do Programa Nacional de Controle e Erradicação da Brucelose e Tuberculose - PNCEBT, publicado, inicialmente, na Instrução Normativa $\mathrm{N}^{\circ} 2$, de 10 de janeiro de 2001 (Brasil 2001).

Apesar de a vacinação de vacas adultas ter sido utilizada em alguns programas internacionais de erradicação, o programa nacional vigente preconiza apenas a vacinação de bezerras entre três e oito meses de vida, e busca alternativas de proteção para animais adultos de regiões com alta incidência (Brasil 2004).

$\mathrm{O}$ uso de doses reduzidas da vacina $\mathrm{B} 19 \mathrm{em}$ bovinos adultos foi praticado por alguns países que a consideram bastante útil, contudo, gera polêmica por induzir resposta imunológica humoral semelhante à que ocorre na infecção natural, o que pode dificultar o diagnóstico sorológico.

A possibilidade de outros métodos de vacinação serem utilizadas pelo PNCEBT no combate à brucelose, na tentativa de flexibilizar o programa, motivou a elaboração deste trabalho, que teve por objetivo avaliar o desempenho de dose reduzida da vacina B19 em rebanho bovino adulto, por meio de técnicas de diagnóstico sorológico: ensaio indireto de imunoadsorção enzimática (ELISA ID), antígeno acidificado tamponado (AAT), 2mercaptoetanol (2-ME), soroaglutinação lenta em tubos (SAL) e fixação de complemento (FC).

\section{MATERIAL E MÉTODOS}

Rebanho. Para o presente estudo foram usadas 62 fêmeas bovinas cruzadas de Nelore, clinicamente sadias, com idade igual ou superior a 24 meses, todas gestantes de aproximadamente quatro meses. Os animais haviam sido testados para a brucelose 30 dias antes da vacinação experimental, por meio das provas de diagnóstico sorológico: AAT, 2-ME, SAL, FC e ELISA ID, obtendo resultados negativos em todas as técnicas.

As vacas pertenciam a uma propriedade rural que se dedica à pecuária de corte e apresenta problemas esporádicos de aborto, e foram mantidos isolados do rebanho em piquetes de Brachiaria brizantha, em sistema extensivo de criação, recebendo água e sal mineral à vontade.

Coleta de soros sangüíneos. Foram coletadas amostras de sangue dos animais através de punção da veia jugular externa com agulhas estéreis. Após a centrifugação a $1.500 \mathrm{~g}$ durante 15 minutos, as amostras de soro foram submetidas às cinco provas sorológicas.

Vacinação. A vacinação dos animais foi realizada por via subcutânea, na região pré-escapular, com uso de dose reduzida de vacina B19 contendo aproximadamente $6 \times 10^{8}$ unidades formadoras de colônia (UFC). A dosagem foi obtida a partir da diluição 1/100, em solução fisiológica estéril, de vacina comercial $^{6}$, oficialmente controlada para conter, no mínimo, 60 × $10^{9}$ UFC por dose e confirmada por método de contagem de bactérias viáveis em suspensão.

Contagem de bactérias viáveis em suspensão da vacina. Foi realizada a contagem de bactérias viáveis de amostra vacinal 19 de B. abortus, pelo método do Departamento de Agricultura dos Estados Unidos (Alton et al. 1976), antes e após a diluição da vacina, para a confirmação da quantidade de UFC por dose em amostras da partida da vacina utilizada na vacinação do rebanho.

Acompanhamento clínico. Durante o período entre a primeira (que ocorreu 30 dias antes da vacinação) e a última coleta do estudo (realizada 3 meses após a vacinação), o que compreendeu quatro meses, o rebanho foi vistoriado, diariamente, para a verificação da ocorrência de abortos, pela observação clínica das fêmeas em gestação. Amostras de placenta de feto abortado e de secreção vaginal foram enviadas ao Instituto Biológico de São Paulo, para realização de exame de reação de polimerase em cadeia (PCR) para a deteç̧ão de Brucella spp.

Provas imunológicas de soroaglutinação. A realização e a interpretação das provas de SAL, 2-ME e AAT seguiram as recomendações de Madruga et al. (2001), respeitando a metodologia de interpretação contida no PNCEBT, em que os resultados da 2-ME e da SAL são avaliados juntos (Brasil 2001).

Prova de fixação de complemento. Na reação de FC foi usada uma técnica de microfixação, com $50 \%$ de hemólise, descrita por Alton et al. (1988), com incubação a quente nas duas fases da reação e cinco unidades hemolíticas de complemento. $O$ complemento usado consistiu de soro de cobaia, com sistema hemolítico formado por hemácias de carneiro padronizadas em fotômetro a um comprimento de onda de $540 \eta \mathrm{m}$, em uma concentração contendo 0,95 gramas de hemoglobina por $100 \mathrm{~mL}$, e anticorpos de coelho contra hemácias de carneiro. Na interpretação dos resultados foram considerados positivos os títulos iguais ou superiores a 1:4.

Ensaio indireto de imunoadsorção enzimática. A técnica de ELISA ID foi realizada seguindo a metodologia descrita no kit ELISA brucelose ${ }^{7}$, que contém microplacas com orifícios adsorvidos com antígeno lipopolissacarídeo de B. abortus, soros controles positivo e negativo (com azida sódica), solução tampão de diluição, solução tampão de lavagem, conjugado monoclonal anti-lgG bovina marcado com peroxidase, substrato tetrametilbenzidina, e solução stop $\left(\mathrm{H}_{2} \mathrm{SO}_{4}\right.$, $0,5 \mathrm{M})$. A densidade ótica (DO) de cada amostra foi lida usando o leitor de ELISA com um filtro de $450 \mathrm{~nm}$. As médias das DOs dos controles positivo e negativo e as DOs de cada soro testado foram calculadas.

\footnotetext{
${ }^{6}$ Vacina Anabortina Bovina B19, Merial, lote de partida 017/01.

${ }^{7}$ Kit ELISA brucelose, Institut Pourquier, lote de partida 041.
} 
O critério de validação da técnica utilizou um valor mínimo de 0,35 para a DO do controle positivo e a média entre a DO do controle positivo e a DO do controle negativo com valor igual ou maior a três. Na interpretação dos resultados, o percentual de positividade $(\mathrm{S} / \mathrm{P} \%)$ foi calculado pela fórmula: $\mathrm{S} / \mathrm{P} \%=(\mathrm{DO}$ da amostra teste $/ \mathrm{DO}$ do soro controle positivo) x 100 . Considerou-se negativa a amostra com $\mathrm{S} / \mathrm{P} \%$ $=90 \%$, suspeita a amostra com $\mathrm{S} / \mathrm{P} \%$ entre $90 \%$ e $100 \%$ e positiva a amostra com $\mathrm{S} / \mathrm{P} \%=100 \%$.

Antígenos. Para as provas de SAL e 2-ME foi usado antígeno padrão comercial ${ }^{8}$, na $\mathrm{FC}$ foi usado antígeno padrão produzido pelo Instituto Biológico de São Paulo, e na AAT, antígeno padrão comercial importado 9 .

Avaliação do rebanho vacinado por técnicas sorológicas. Três meses após a vacinação com dose reduzida da vacina B19, o rebanho sofreu coleta de amostras de soro para avaliação pelas cinco técnicas propostas.

Determinação da sensibilidade e especificidade relativas. A sensibilidade e a especificidade relativas das provas de AAT, SAL com 2-ME e ELISA ID foram calculadas em relação aos resultados obtidos na prova de FC, tida como referência por ser considerada prova confirmatória pelo PNCEBT. Os cálculos correspondem às fórmulas abaixo (Sánches-Vizcaíno \& Alvarez 1987, Madruga et al. 2001):

Resultado do teste de referência

$\begin{array}{llll} & & + & - \\ \text { Resultado do } & + & \text { A } & \text { C } \\ \text { teste estudado } & - & \text { B } & \text { D } \\ \text { Sensibilidade }=[\mathrm{A},(\mathrm{A}+\mathrm{B})] \times 100 & \\ \text { Especificidade }=[\mathrm{D},(\mathrm{D}+\mathrm{C})] \times 100\end{array}$

Análise estatística. O teste de Qui-quadrado $\left(\chi^{2}\right)$ foi usado para verificar a frequiência de resultados positivos obtidos pelos diferentes métodos sorológicos utilizados no experimento (Centeno 2001).

\section{RESULTADOS}

O Quadro 1 mostra o número de indivíduos reagentes positivos e negativos diagnosticados pelas provas de AAT e FC, e o cálculo da relação das especificidade e sensibilidade da AAT para a FC. Da mesma forma, o Quadro 2 mostra os resultados das provas de 2-ME com SAL em relação à $\mathrm{FC}$, e o Quadro 3, da prova de ELISA ID em relação à FC.

Todas as técnicas de diagnóstico de brucelose usadas no rebanho, conhecidamente negativo para a enfermidade, apresentaram uma alta taxa de resultados positivos que não pode ser

Quadro 1. Sensibilidade (S) e especificidade (E) relativas da prova do antígeno acidificado tamponado (AAT), calculadas com base nos resultados da reação de fixação de complemento (FC)

\begin{tabular}{cccc}
\hline AAT & \multicolumn{2}{c}{ FC } & Total \\
\cline { 2 - 3 }+ & + & - & \\
\hline- & 29 & 13 & 42 \\
Total & 0 & 20 & 20 \\
\hline $\mathrm{S}=100 \%$. & 29 & 33 & 62 \\
$\mathrm{E}=60,6 \%$. & & & \\
& & &
\end{tabular}

\footnotetext{
${ }^{8}$ Antígeno para diagnóstico da brucelose, prova lenta em tubo, TECPAR, lote de partida 002./01.

${ }^{9}$ Antigène brucellique Rose Bengale, Institut Pourquier, lote de partida 278 .
}

Quadro 2. Sensibilidade (S) e especificidade (E) relativas da prova de 2-mercaptoetanol (2-ME) com soroaglutinação lenta (SAL), calculadas com base nos resultados da reação de fixação de complemento (FC)

\begin{tabular}{cccc}
\hline 2-ME com SAL & \multicolumn{2}{c}{ FC } & Total \\
\cline { 2 - 3 } & + & - & \\
\hline+ & 29 & 25 & 54 \\
Total & 0 & 8 & 8 \\
$\mathrm{~S}=100 \%$. & 29 & 33 & 62 \\
$\mathrm{E}=24,4 \%$. & & & \\
& & &
\end{tabular}

Quadro 3. Sensibilidade (S) e especificidade (E) relativas da prova de ensaio indireto de imunoadsorção enzimática (ELISA ID), calculadas com base nos resultados da reação de fixação de complemento (FC)

\begin{tabular}{cccc}
\hline \multirow{2}{*}{ ELISA ID } & \multicolumn{2}{c}{ FC } & Total \\
\cline { 2 - 3 } & + & - & \\
\hline+ & 29 & 33 & 62 \\
- & 0 & 0 & 0 \\
Total & 29 & 33 & 62 \\
\cline { 1 - 1 }$=100 \%$. & & & \\
$\mathrm{E}=0 \%$. & & & \\
& & &
\end{tabular}

Quadro 4. Números de reagentes positivos e negativos obtidos pelos métodos de fixação de complemento (FC), antígeno acidificado tamponado (AAT), 2-mercaptoetanol (2-ME) com soroaglutinação lenta (SAL), e ensaio indireto de imunoadsorção enzimática (ELISA ID)

\begin{tabular}{lcccc}
\hline \multirow{2}{*}{ Resultados } & \multicolumn{4}{c}{ Método } \\
\cline { 2 - 6 } & FC & AAT & 2-ME com SAL & ELISA ID \\
\hline № positivos (\%) & $29(46,77)$ & $42(67,74)$ & $54(87,09)$ & $62(100)$ \\
№ negativos (\%) & $33(53,23)$ & $20(32,26)$ & $8(12,91)$ & $0(0)$
\end{tabular}

Quadro 5. Análise estatística das frequiências dos métodos de diagnóstico de fixação de complemento (FC), antígeno acidificado tamponado (AAT), 2-mercaptoetanol (2-ME) com soroaglutinação lenta (SAL), e ensaio indireto de imunoadsorção enzimática (ELISA ID)

Método Porcentagem de positivo

FC $46,77 \quad B^{\mathrm{a}}$

AAT $67,74 \quad C$

2-ME com SAL $87,09 \quad$ D

ELISA ID 100

aporcentagens seguidas de letras diferentes são estatisticamente diferentes entre si pelo teste de $X^{2}$ no nível de $5 \%$.

explicada pela prevalência da doença na população estudada, portanto, assumiu-se que os resultados positivos encontrados são um reflexo da falta de especificidade dos métodos em situações de titulação de anticorpos causados por reação vacinal. $O$ Quadro 4 mostra o número de indivíduos reagentes positivos e negativos nas provas de FC, AAT, 2-ME com SAL e ELISA ID.

Em função do exposto, partiu-se para a comparação de frequiência de resultados positivos obtidos pelos diferentes métodos, considerando que os métodos que apresentaram frequiências mais baixas são aqueles mais específicos e menos susceptí- 
veis a erros de diagnóstico decorrentes da vacinação. O Quadro 5 mostra os resultados obtidos desta análise estatística, na qual utilizou-se o teste do Qui-quadrado ao nível de 5\%.

\section{DISCUSSÃO}

O programa de controle da brucelose, no Brasil, esteve regulamentado pela Portaria ministerial 23/76, desde 1976, pelas Normas para a Profilaxia da Brucelose Animal. Para a proteção dos rebanhos, as regras de combate à doença preconizavam a vacinação de bezerras, uma única vez, e o uso das técnicas de soroaglutinação rápida (SAR) e SAL como provas sorológicas oficiais. As técnicas de FC, precipitação pelo rivanol, 2-ME, AAT e prova individual do anel do leite eram utilizadas em rebanhosproblema para dirimir eventuais dúvidas (Ferrari 2001). Essa prática não alcançou o resultado desejado no controle da enfermidade no país, mantendo-o com o mesmo status sanitário em relação à brucelose.

A Portaria 23/76 permitia a imunização de fêmeas adultas em propriedade afetada, por meio de requerimento e autorização dos órgãos competentes, desde que observadas algumas condições como a da vacinação ser realizada apenas uma vez (Kuchembuck 1997). Os poucos dados publicados sobre os resultados das medidas adotadas, sugerem uma falta de estrutura do programa. A intenção de colocar as ações sanitárias nacionais em sintonia com as ações usadas pelos países compradores de produtos de origem bovina parece ter impulsionado a elaboração e a execução de novas diretrizes.

Atualmente, no Brasil, está em vigor o Regulamento Técnico do Programa Nacional de Controle e Erradicação da Brucelose e Tuberculose, publicado na Instrução Normativa $\mathrm{N}^{\circ} 6$, de 08 de janeiro de 2004 (Brasil 2004), que obriga a vacinação, em todo território nacional, de todas as fêmeas das espécies bovina e bubalina, na faixa etária de três a oito meses, com a vacina B19, respeitando as normas definidas pelo Comitê de Especialistas em Padrões Biológicos da Organização Mundial da Saúde, que, em 1970, estabeleceu uma padronização da dose, por animal, de 40 a $120 \times 10^{9}$ bactérias viáveis, para injeção subcutânea (dose padrão).

A vacina B19, quando aplicada em animais com idade superior a oito meses, induz o surgimento de títulos de anticorpos que podem dificultar o diagnóstico (Poester et al. 2000, Mathias et al. 2001), e que, quando presentes, são detectados pelas técnicas de diagnóstico convencionais, pelo ELISA ID e pela FC, que não conseguem diferenciar anticorpos vacinais dos induzidos por infecção de campo (Viana et al. 1982, Costa et al. 1999, Ferraz 1999, Megid et al. 1999, Samartino et al. 1999). Os anticorpos vacinais não são detectados em animais adultos quando a vacinação com dose padrão respeita a idade preconizada pelo PNCEBT, pois, nestes casos, a titulação se estende, normalmente, até os 18 meses de idade (Costa et al. 1999).

O PNCEBT não permite a vacinação de animais adultos com nenhuma vacina, incluindo a B19, o que preocupa os pecuaristas, que não têm outra opção além do sacrifício (abate sanitário) e destruição dos soropositivos, mesmo que esses representem mais de cinqüenta por cento do rebanho total, o que se torna mais crítico pelo fato de o sacrifício não reverter capital suficiente para a reposição do rebanho e pela destruição significar apenas perda. A atual legislação não prevê apoio a esses casos, assim como não orienta qual o melhor manejo a ser adotado com os bezerros das vacas soropositivas que mamam em suas mães; nestes casos, a eliminação, como única saída, poderia inviabilizar a atividade.

Diversos autores citam a proteção de bovinos à exposição a desafios de virulência, com aumento da resistência a abortos, alcançada com o uso de doses reduzidas da vacina B19 em animais adultos (Plommet \& Fensterbank 1976, Nicoletti et al. 1978, Nicoletti 1984, Confer et al. 1985). A dose protetora mínima da vacina B19 está entre $10^{10}$ e $10^{7}$ UFC. Apesar dos efeitos benéficos do uso desse método de vacinação, títulos de anticorpos residuais induzidos por vacina, reações sorológicas e persistência de infecção com a amostra podem ocorrer e causar reações falso-positivas nos testes de diagnóstico sorológico, e um pequeno aumento da dose de desafio pode resultar em aumento nas taxas de aborto (Confer et al. 1985).

Com base em informações da Comissão Técnica da Brucelose dos Estados Unidos, em 1982, o Manual de Métodos e Regulamentos para o controle da brucelose passou a contemplar, entre as estratégias adotadas, $\mathrm{o}$ uso da vacina B19 em fêmeas bovinas maiores de 12 meses, com dose contendo entre $3 \times 10^{8}$ e $10^{9}$ bactérias viáveis. Essas modificações ocorreram sob o respaldo dos resultados de diversas pesquisas, demonstrando que doses reduzidas da vacina podiam conferir a fêmeas adultas imunidade pelo menos igual à produzida pela vacinação de bezerras, com resposta sorológica retornando à condição negativa cerca de três meses após a vacinação. Assim, até 1996 a dose reduzida da B19 foi a única vacina aprovada para uso em animais adultos naquele país (Ferraz 1999).

Os órgãos oficiais dos EUA, responsáveis pela erradicação da brucelose, afirmavam que o método provou ser útil em rebanhos-problema classificados numa das seguintes características: 1) rebanho com mais de 200 animais cronicamente infectados; 2) rebanho com infecção aguda, em que há aborto e doença com rápida disseminação, com alto potencial de exposição no início do curso do surto; e 3) rebanhos não infectados, mas com alto risco de infecção. Todas essas situações são comuns em nosso meio, e nós não estamos autorizados pelos órgãos oficiais a utilizar métodos atualizados e disponíveis, muito embora Viana et al. (1982) e Kuchembuck (1984) citados por Kuchembuck (1997) tenham mostrado que a vacinação com dose reduzida em rebanhos-problema protegem contra o aborto e outros sinais clínicos, evitam a disseminação da doença e diminuem o número de animais reagentes positivos no decorrer de curto período.

$O$ presente estudo teve o intuito de avaliar o uso de dose reduzida da vacina $B 19$, por meio de provas imunológicas de diagnóstico, preconizadas pelo PNCEBT: AAT, 2-ME com SAL e FC, e por outra não usada pelo programa, a ELISA ID. Vacas gestantes, negativas para a brucelose pelas técnicas citadas, foram vacinadas com dose de aproximadamente $6 \times 10^{8}$ bactérias viáveis, o que corresponde ao dobro da dose mínima considerada por Alton et al. (1984) capaz de imunizar vacas prenhes em início de gestação.

Os resultados obtidos, após três meses da vacinação, são de que todas as técnicas sorológicas usadas detectaram animais 
soropositivos no rebanho. Estes dados revelam que as titulações encontradas se devem, provavelmente, à reação vacinal residual dos animais que podem ser considerados falso-positivos. Os resultados não estão de acordo com os obtidos por Ferrari (2001), que, utilizando a mesma dose reduzida em rebanho adulto, concluiu que esta técnica vacinal não interfere no diagnóstico sorológico feito por meio das técnicas de SAR, SAL, 2-ME, AAT e FC, realizados nos períodos de 90, 210 e 320 dias após a vacinação.

A prova de fixação de complemento foi escolhida como referência para a comparação com outras técnicas nos cálculos de sensibilidade e especificidade, pois, de acordo com alguns autores (Nicoletti et al. 1978, Samartino et al. 2000, Brasil 2001, Molnár et al. 2002), a FC é uma prova bastante fidedigna, de alta especificidade, que apresenta melhor equilíbrio entre os parâmetros avaliados, o que permite definir títulos sorológicos controversos pelas técnicas convencionais, tendo se tornado, em diversos países, a técnica de diagnóstico definitivo. A FC é considerada prova de referência recomendada pela "Organização Internacional de Epizootias" (OIE) para o trânsito internacional de animais (Brasil 2003).

Como a FC também detectou resultados falso-positiovos, partiu-se então para a comparação de frequiência, através do teste do $X^{2}$, dos resultados positivos obtidos pelos diferentes métodos de diagnóstico, considerando que os métodos que apresentaram frequiências mais baixas são aqueles mais específicos e menos susceptíveis a erros de diagnóstico decorrentes da vacinação. Nenhum teste apresentou resultados semelhantes a um outro, e as porcentagens de positivos foram de $46,77 \%$ para a FC, de $67,74 \%$ para a AAT, de $87,09 \%$ para a SAL com 2-ME e de $100 \%$ para o ELISA ID, que os coloca, respectivamente, na ordem decrescente de especificidade, sendo a FC a menos susceptível, e a técnica de ELISA ID, a mais susceptível a erros de diagnóstico em bovinos vacinados em idade adulta, com dose reduzida, no período de noventa dias após vacinação.

O uso de dose reduzida na vacinação de animais adultos é de difícil decisão. Existem, de fato, dados que oferecem embasamento científico suficiente para o PNCEBT adotar a utilização desta técnica em rebanhos-problema, contudo, pelo presente estudo, o método representa riscos maiores de perdas econômicas ao produtor, pois vacas vacinadas adultas que, após a vacinação, apresentassem reações positivas, diga-se falso-positivas, deveriam ser eliminadas. Em outra linha de raciocínio, a permanência de vacas não vacinadas no rebanho poderia acarretar maiores perdas por aborto.

Durante os três meses que se seguiram após a vacinação, apenas uma vaca abortou. Amostras de placenta e de secreção vaginal, colhidas um dia após o aborto, foram submetidas à técnica de PCR, que não detectou Brucella spp. Pelo 'Manual Técnico do PNCEBT' (Brasil 2003), a PCR permite a identificação da $B$. abortus em material de aborto e nas secreções da vaca após o parto ou aborto, sendo uma prova de diagnóstico direto considerada de alta confiabilidade. Considerando o resultado da PCR, o método vacinal usado não causou aborto no rebanho.

Na opção por vacinar animais adultos com dose reduzida da vacina B19, este método poderia ser usado, uma única vez em cada propriedade, de imediato e após estudo sorológico de todo o rebanho, apenas em vacas com resultado negativo confirmado, mantendo-as isoladas do restante do rebanho. Os cuidados complementares deveriam ser principalmente com os animais de reposição e com a adoção das outras medidas de controle já previstas no Manual Técnico do PNCEBT, como a vacinação de bezerras, testes sorológicos periódicos e eliminação dos reagentes positivos. Nesses rebanhos, essas ações em conjunto poderiam auxiliar na diminuição de altas prevalências, reduzindo perdas econômicas para os proprietários devido ao aborto decorrente da infecção por B. abortus.

Os resultados obtidos, nas condições do presente trabalho, permitem concluir que o emprego de uma dose reduzida da vacina B19 interfere no diagnóstico sorológico do rebanho, e que também nenhuma das técnicas de diagnóstico utilizadas apresentou especificidade adequada para uso em bovinos vacinados em idade adulta, com dose reduzida, no período de três meses após vacinação.

\section{REFERÊNCIAS}

Alton G.G., Jones L.M. \& Pietz D.E. 1976. Las Tecnicas de Laboratorio en la Brucelosis. $2^{\text {a }}$ ed. Organizacion Mundial de la Salud, Genebra. 175p.

Alton G.G., Corner L.A. \& Plackett P. 1984. Vaccination against bovine brucellosis. Dev. Biol. Stand. 56:643-647.

Alton G.G., Jones L.M., Angus R.D. \& Verger J.M. 1988. Techniques for the Brucellosis Laboratory. Institut National de la Recherche Agronomique, Paris. 190p.

Brasil 2001. Regulamento Técnico do Programa Nacional de Controle da Brucelose e da Tuberculose Animal. Departamento de Defesa Animal, Secretaria de Defesa Agropecuária, Ministério da Agricultura e do Abastecimento, Brasília.

Brasil 2003. Manual técnico do Programa Nacional de Controle e Erradicação da Brucelose e Tuberculose - PNCEBT: versão preliminar. Departamento de Defesa Animal, Secretaria de Defesa Agropecuária, Ministério da Agricultura, Pecuária e Abastecimento, Brasília.

Brasil 2004. Regulamento Técnico do Programa Nacional de Controle da Brucelose e da Tuberculose Animal. Departamento de Defesa Animal, Secretaria de Defesa Agropecuária, Ministério da Agricultura e do Abastecimento, Brasília.

Centeno A.J. 2001. Curso de Estatística Aplicado à Biologia. 2a ed. Editora da Universidade Federal de Goiás, Goiânia. 234p.

Confer A.W., Hall S.M., Faulkner C.B., Espe B.H., Deyoe B.L., Morton R.J. \& Smith R.A. 1985. Effect of challenge dose on the clinical and immune responses of cattle vaccinated with reduced doses of Brucella abortus strain 19. Vet. Microbiol., Amsterdam, 10:561-575.

Costa G.M., Abreu V.L.V., Lobato F.C.F., Silva J.A. \& Martins N.E. 1999. Avaliação do teste de imunodifusão mediante emprego do polissacarídeo "O" no diagnóstico da brucelose bovina. Arq. Bras. Med. Vet. Zootec. 51(4):317-322.

Ferrari C.I.L. 2001. Avaliação do uso de uma dose reduzida da vacina produzida com a amostra B19 de Brucella abortus em rebanho bovino naturalmente infectado. Dissertação, Faculdade de Medicina Veterinária e Zootecnia, Universidade Estadual Paulista, Botucatu, SP. 79p.

Ferraz I.B.F. 1999. Novos métodos de controle e diagnóstico da brucelose bovina. Revta Bras. Reprod. Anim., Belo Horizonte, 23(4):504-508.

Kuchembuck M.R.G. 1997. Brucelose. Biológico, São Paulo, 59(1):33-35.

Madruga C.R., Araújo F.R. \& Soares C.O. 2001. Imunodiagnóstico em Medicina Veterinária. Embrapa Gado de Corte, Campo Grande, MS. 360 p.

Mathias L.A., Chaves L.F., Chen A.A., Girio R.J.S. \& Neto W.V. 2001. Evolução de títulos sorológicos, nas provas de soroaglutinação em placa, 
antígeno acidificado tamponado e fixação de complemento, em bezerras Nelore vacinadas aos 18 meses de idade com Brucella abortus amostra B 19. Pesq. Vet. Bras. 21(4):139-142.

Megid J., Ribeiro M.G., Agottani J.V.B. \& Marcos G.Jr 1999. Imunodifusão em gel de ágar com polissacarídeos de membrana de Brucella abortus B19-3 no diagnóstico da brucelose bovina. Arq. Bras. Med. Vet. Zootec. 51(5):433-437.

Megid J., Ribeiro M. G., Marcos G.Jr \& Crocci A.J. 2000. Avaliação das provas de soroaglutinação rápida, soroaglutinação lenta, antígeno acidificado e 2-mercaptoetanol no diagnóstico da brucelose bovina. Braz. J. Vet. Res. Anim. Sci. 37(5). Disponível em: <www.scielo.br>. Acesso em: 24 Fev. 2003.

Molnár L., Molnár E., Túry E. \& Souza J.S. 1997. Concepções modernas para o diagnóstico da brucelose. Revta Bras. Med. Vet. 19(4):157-162.

Molnár E., Molnár L., Dias H.L.T., Souza J.S. \& Vale W.G. 2000. Ocorrência de brucelose bovina no Estado do Pará confirmada por métodos sorológicos. Revta Bras. Med. Vet. 22(3):117-121.

Molnár L., Molnár E., Lima E.C. \& Dias H.L.T. 2002. Avaliação de seis testes sorológicos no diagnóstico da brucelose bubalina. Pesq. Vet. Bras. 22(2). Disponível em: <www.scielo.br>. Acesso em: 2 Set. 2002.

Nicoletti P., Jones L.M. \& Berman D.T. 1978. Adult vaccination with standard and reduced doses of Brucella abortus strain 19 vaccine in a dairy herd infected with brucellosis. J. Am. Vet. Med. Assoc. 173(2):1445-1449.
Nicoletti P. 1984. Vaccination of cattle with Brucella abortus strain 19 administered by differing routes and doses. Vaccine 2:133-135.

Poester F.P., Ramos E.T., Gomes M.J.P., Chiminazzo C. \& Schurig G. 2000. The serological response of adult cattle after vaccination with Brucella abortus strain 19 and RB51. Braz. J. Vet. Res. Anim. Sci. 37(1). Disponível em: <www.scielo.br>. Acesso em: 19 Fev. 2003.

Plommet M. \& Fensterbank R. 1976. Vaccination against bovine brucellosis with a low dose of strain 19 administered by the conjunctival route. III. Serological responses and immunity in the pregnant cow. Ann. Rech. Vet. 7(1):9-23

Samartino L., Gregoret R., Gall D. \& Nielsen K. 1999. Fluorescence polarization assay: application to the diagnosis of bovine brucellosis in Argentina. J. Immunoassay 20(3):115-126.

Samartino L., Buffoni L., Conde S. \& Gregoret R. 2000. Nuevas metodologías para el diagnóstico serológico de la brucelosis bovina. Revta Med. Vet., B.Aires, 82(2):90-94.

Sánches-Vizcaíno J.M. \& Alvarez M.C. 1987. Enzyme Immunoassay Techniques, ELISA, in Animal and Plant Diseases: 2nd ed. Technical Series 7, OIE - Office International des Epizooties, Instituto Nacional de Investigaciones Agrarias, Madrid. 54p.

Viana F.C., Villela L.G., Silva J.A., Mendes J.E., Moreira E.C. \& Dias T.D. 1982. Vacinação contra brucelose bovina com dose reduzida da vacina (amostra 19) por via conjuntival. Arq. Esc. Vet. Univ. Fed. Minas Gerais 34:279-87. 